\title{
Clinical features of patients with pituitary stalk thickening: a review of 159 cases from one medical center
}

Yanjiao Cai ${ }^{1+}$, Xuefei Shou ${ }^{2+}$, Zhaoyun Zhang ${ }^{1}$, Hongying Ye ${ }^{1}$, Yao Zhao ${ }^{2}$, Yongfei Wang ${ }^{2}$, Rong Xie ${ }^{2}$, Shiqi $\mathrm{Li}^{2}$ and Yiming $\mathrm{Li}^{1^{*}}$

\begin{abstract}
Background: Pituitary stalk thickening (PST) used as an imaging diagnosis plays a major role in diagnosis and treatment of the hypothalamus and pituitary disease at an early stage. Up until now, several lines of systematic investigations have been conducted among adolescents, and the results indicated that PST is possibly one of the principal early manifestations of sellar region tumor. To characterize the major clinical features of PST and to identify the most effective treatments we conducted this study.

Methods: This was a retrospective review of patients with PST evaluated at Huashan Hospital over an eight-year period between 2007 and 2014. One hundred fifty nine patients who were diagnosed PST were included. The data including demographics, clinical presentations, imaging examinations, laboratory results and surgery were thoroughly reviewed and carefully analyzed. According to their clinical presentations and examinations, relevant treatments were adopted and different prognosis were observed.

Results: Of the 159 patients, 57 were males and 102 were females (median age was 29 and $43.4 \%$ were under the age of 21 years). And of the patients in the age group between 30 and 35 years, 84\% were females. "Polydipsia and polyuria" was the most common clinical manifestation observed in 90 cases (>50\%). 49.5\% of the patients were diagnosed to have at least one anterior pituitary dysfunction. The sellar region MRI (SR-MRI) data showed that patients who had different clinical presentations or pituitary function showed different SR-MRI appearance. Over 60\% patients who performed followup MRI showed shrunken PST. Fourteen cases who received radiotherapy appeared to be improved as shown by MRI.

Conclusions: PST is most commonly seen in the teenagers and the women of reproductive age. Distinct etiology may be identified based on the clinical manifestations, age and SR-MRI, which would help to make the final decision for treatments. Radiotherapy and immuno-suppressed therapy are effective in alleviating clinical symptoms and shrinking the stalk thickening.
\end{abstract}

Keywords: Pituitary stalk thickening, Central diabetes insipidus, Hypopituitarism, Radiotherapy, Immuno-suppressed therapy

\footnotetext{
* Correspondence: shhlym@126.com

†Equal contributors

${ }^{1}$ Department of Endocrinology and Metabolism, Huashan Hospital, Shanghai

Medical College, Fudan University, 12 Wulumuqi Zhong Road, Shanghai

200040, China

Full list of author information is available at the end of the article
} 


\section{Background}

Pituitary stalk thickening (PST) is an imaging diagnosis defined as pituitary stalk diameter above $3.5 \mathrm{~mm}$ on sellar region magnetic resonance imaging (SR-MRI) [1, 2]. Pituitary stalk lesion has a broad range of etiological spectrum which can be categorized into three major groups: congenital disease, inflammatory disease, tumor and a multitude of subgroups [3]. And previous studies have suggested that PST is possibly one of the principal early manifestations of sellar region tumor, which is commonly found in children and young adults $[4,5]$. However a single mainstream modality of effective treatment has not yet been established and clinical diagnosis is often formed merely on the basis of clinical presentations and imaging findings. Herein we reviewed our Huashan Hospital experience with PST.

\section{Methods}

Patient demographics and case selection

We conducted a retrospective review of 197 patients with pituitary stalk lesions evaluated at Huashan Hospital from 2007 to 2014. Of these patients, 38 cases were excluded due to lack of clinical data. Among the 159 cases included, 102 were women and 57 were male. The average age was 27.6 years ranging from 2 to 80 years (Fig. 1). It is particularly worth mentioning that young patients under 21 years account for as much as $43.4 \%$ (69 cases). In female, most patients fell to two age
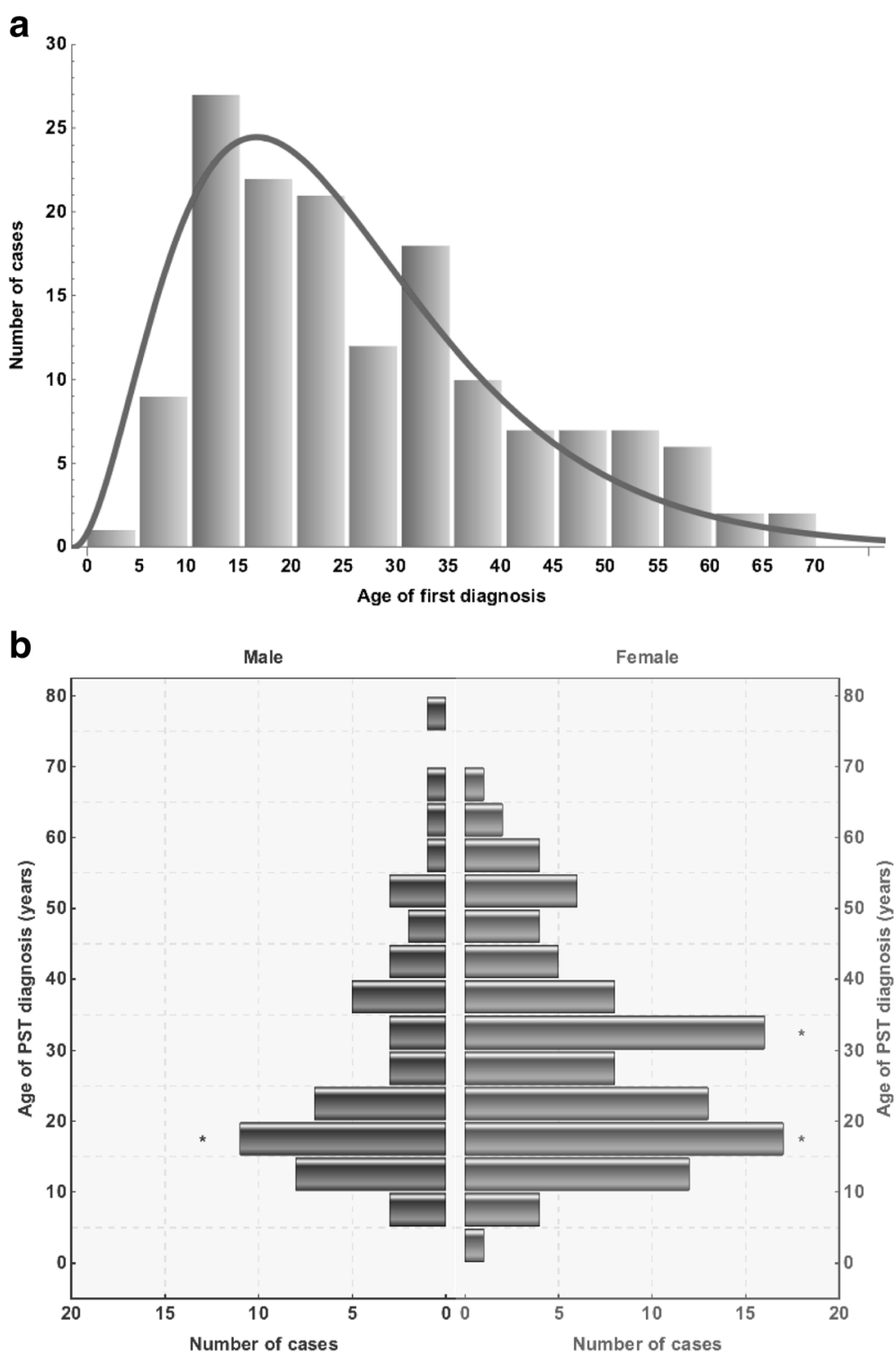

Fig. 1 The distribution of demographics data at diagnosis. a shows two peak among age 10-15 and age 30-35, and in b male has only one peak among age 10-15 while female distributes two peak 
groups including 15 to $20 \mathrm{yr}$ and 30 to $35 \mathrm{yr}$. However, in male, most patients were at 15 - to 20 -age group.

\section{Diagnosis}

We reviewed all available demographical, clinical evaluation and physical examination data. The first SR-MRIs from the patients were used to identify pituitary stalk abnormality. In addition, a broad array of endocrine functions were evaluated including thyroid stimulating hormone (TSH), free triiodothyronine (FT3), free thyroxine (FT4), fludrocortisol (F)(8 am), adrenocorticotropic hormone (ACTH) $(8 \mathrm{am})$, urinary free cortisol (UFC), growth hormone $(\mathrm{GH})$, insulin-like growth factor type 1 (IGF-1), luteotropic hormone (LH), follicle-stimulating hormone $(\mathrm{FSH})$, estraliol (E2), progesterone $(\mathrm{P})$, testosterone $(\mathrm{T})$, prolactin (PRL), $24 \mathrm{~h}$ urine volume, blood osmolality and urine osmolality. Furthermore, regular follow-ups (annual evaluation of clinical presentation, physical examination, pituitary function and SR-MRI) of these patients provided important comparative evidences. And finally we collected 76 follow-up cases (5.9 $\pm 3.2 \mathrm{yr}$, range from $2-18$ years). In addition to the clinical evaluation and follow-ups, we obtained also biopsy and surgery data from nine patients.

\section{Evaluation of pituitary function}

Anterior hormonal deficiencies were diagnosed based on low levels of serum hormones. In patients with adrenal insufficiency, the insulin tolerance test (ITT) was used for confirmation. As for the ITT, $\mathrm{F}<18 \mathrm{ug} / \mathrm{dl}$ was diagnosed adrenal insufficiency [6]. GH and IGF-1 were measured in 31 patients and some of them have done confirmatory tests. Diabetes insipidus (DI) was diagnosed by typical signs and symptoms, and were documented with the serum and urinary osmolarity; water deprivation tests were performed in 30 patients.

\section{Treatment modalities}

Once diagnosed PST, patients received one of the three treatment modalities, including symptomatic treatment (mainly refer to the improvement of polyuria), radiotherapy (Gamma Knife) or immuno-suppressed therapy (using oral glucocorticoid, usually methylprednisolone $1.0 \mathrm{mg} / \mathrm{kg}^{*} 8$ weeks). Different treatment was made according to clinical presentations, endocrinology evaluation, SR-MRI, together with patients' willingness $[7,8]$. And the effect was depended on follow-up SR-MRI. However thinking of the risk of biopsy and the medical condition in China, some clinical data were lost.

\section{Statistics}

One-sample Kolmogorov-Smirnov Test was used to confirm a normal distribution of the data. Mean \pm SD was used to describe normal distribution data, whereas median and quartile were used to describe abnormal distribution data. The paired $t$ test was used to compare means of continuous variables. Chi-square test was used to compare the difference between categorical variables. A value of $P \leq 0.05$ was considered statistically significant.

\section{Results}

\section{Clinical manifestation}

Of all presenting symptoms, polydipsia and polyuria were the most common ones, which presented in 90 cases (56.6\%) (Fig. 2).The second major symptom was menstrual disorder in females (35 cases out of 37 ), while male would complain of losing libido, which indicating gonadal deficiency. Growth disorder was documented in 8 cases (about 5\%, also accounted for $11.5 \%$ in children population). The other 15 patients claimed to experience symptoms such as headache or diplopia. It is worth noting that 16 patients who had polydipsia and polyuria experienced other symptoms as well. Of those, eight had gonadal dysfunction, three had growth disorder, one had headache and four had other symptoms.

\section{Pituitary functional evaluation}

The assessment of anterior pituitary function was available in 91 patients (Table 1). Blood prolactin was elevated in 33 of 79 patients (42\%).

Adrenal insufficiency was found to be present in 24 of 69 patients $(34.8 \%)$. Of the 78 patients whose thyroid function was examined, deficiency was presented in 15 cases. Evaluation of gonadal function was performed in 70 patients, which showed that 26 of them had gonadal deficiency. As for growth hormone (GH) secretion, 31 patients received evaluation and almost half of them were diagnosed to have GH deficiency (45.2\%). Of all patients, 45 (49.5\%) had at least one deficient anterior pituitary axis and 13 of them had deficiency in two or more axes.

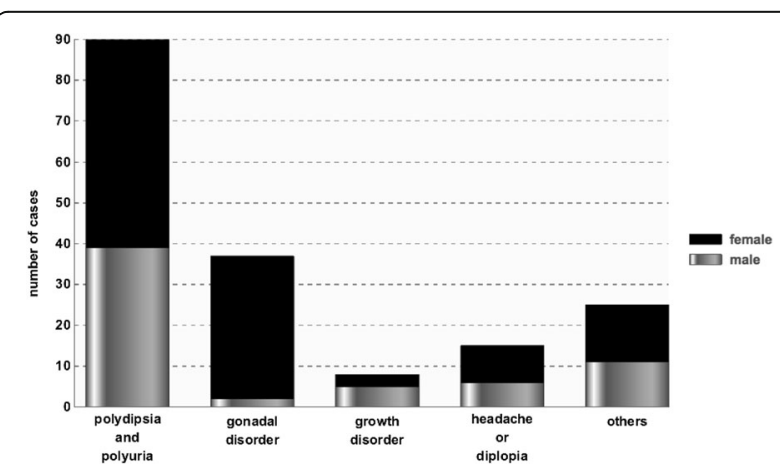

Fig. 2 The clinical manifestation of PST patients. Among the five mostseen clinical manifestation, polydipsia and polyuria accouts for the most, and there is no difference between men and women. The second major symptom was gonadal deficiency, which is more commonly seen in women 
Table 1 hormonal evaluation in PST

\begin{tabular}{llc}
\hline & Cases & Percentage(\%) \\
\hline Adrenal Axis dysfunction & 24 & 34.8 \\
Thyroid Axis dysfunction & 15 & 19.2 \\
Gonadal Axis dysfunction & 26 & 37.1 \\
GH Axis dysfunction & 14 & 45.2 \\
Hyperprolactinemia & 33 & 41.8 \\
\hline
\end{tabular}

Ninety patients who claimed to have the symptom of polydipsia and polyuria were analyzed. Based on their clinical presentations along with urine and plasma osmolality, 60 patients were diagnosed as diabetes insipidus, while 16 of them also presented with anterior pituitary dysfunction. Of the 30 patients who had water deprivation test, 25 of them were diagnosed as complete central diabetes insipidus and five as partial central diabetes insipidus.

\section{SR-MRI findings and follow-up data}

For all 159 patients who underwent their initial SRMRIs at our hospital, we divided them into three groups: single pituitary stalk thickened, PST with enlarged pituitary gland, PST together with other suprasellar lesion (each group accounts for 55.3, 32.1 and 12.6\% separately) (Fig. 3). And we also try to analyse the relationship between SR-MRI and clinical presentations or pituitary a
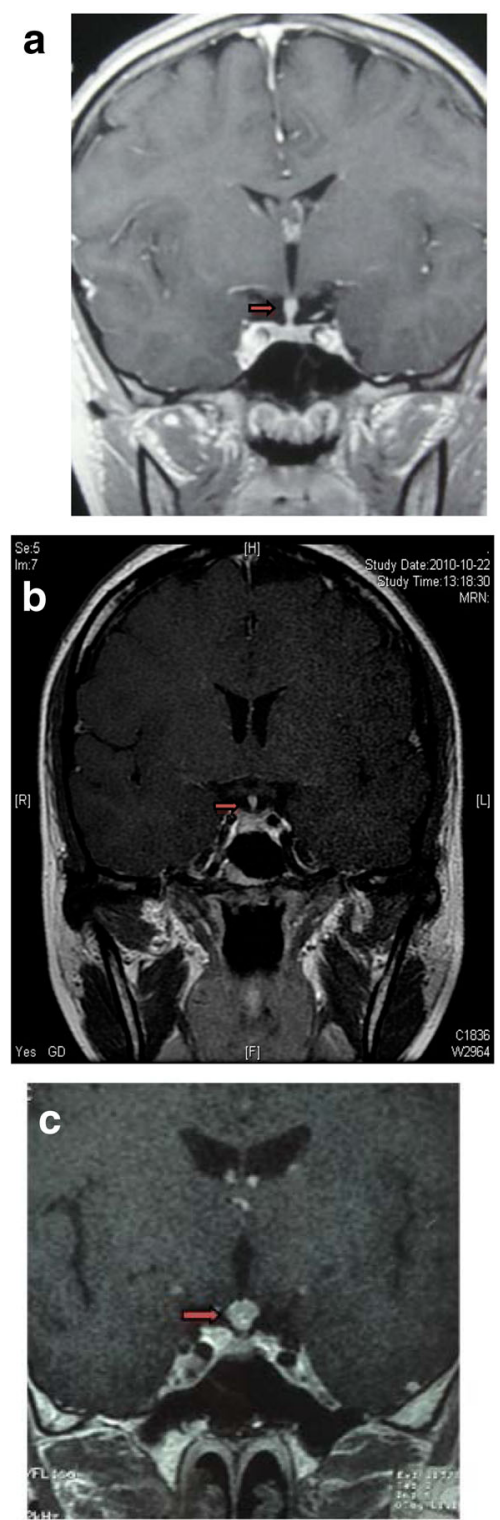
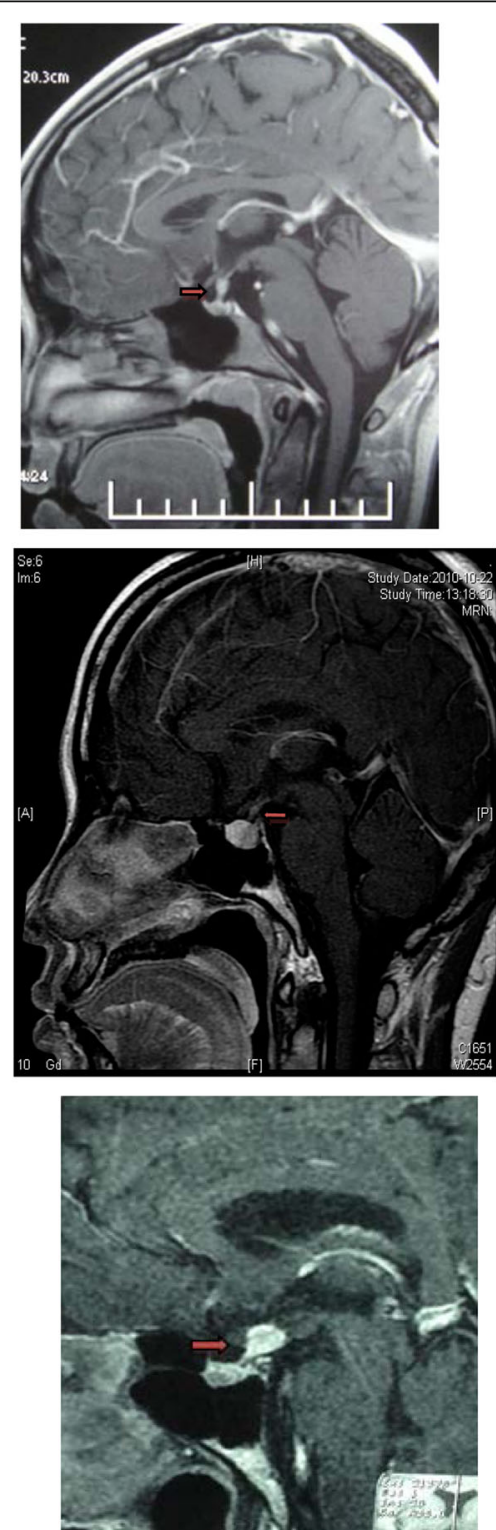

Fig. 3 Different SR-MRI appearance. There were three different SR-MRI appearances: a single pituitary stalk thickened, b PST with enlarged pituitary gland, c PST together with other suprasellar lesion 
function (Fig. 4). Patients with enlarged pituitary gland was more likely to have gonadal deficiency, meanwhile single PST and PST together with suprasellar lesion appeared to have posterior pituitary gland appearance with/without anterior pituitary deficiency (especially growth disorder).

Therefore, we conducted regular follow-ups, and collected 44 post-treatment MRI recordings. The follow-up imaging demonstrated that PSTs in 27 cases (61.4\%) of the patients shrunk, 12 remained unchanged and only five enlarged.

\section{Treatment modalities and follow up}

Among all the follow-up patients (Fig. 5), 5 of the 44 patients didn't receive any treatment but underwent regular follow-up from 6 to 60 months. Surprisingly, their SR-MRIs didn't indicate any noticeable development of PST. And the other patients received one of the three treatment modalities, including symptomatic treatment, radiotherapy or immuno-suppressed therapy. Of the 20 patients who received symptomatic treatment, the thickness of pituitary stalks were decreased in nearly half of them (nine cases), unaltered in six patients and increased in five patients.

Nineteen patients received either radiotherapy (14 cases) or immuno-suppressed therapy (five cases). All 14 patients receiving radiotherapy showed shrinkage in the thickness of pituitary stalk. Among five cases receiving immuno-suppressed therapy, four cases showed shrinkage while one case showed no change.

Finally, nine patients who underwent either surgeries or surgical biopsy were followed up. All these nine patients presented with polyuria and polydipsia (two of which also have amenorrhea, one together with body weight gain and one with growth disorder). Of all the patients, conspicuous mass was seen on SR-MRI in five cases, persistent enhancement was reported in three cases, and one patient underwent a biopsy of his rib first and later PST was discovered. Pathological examination reported 3 germinoma, 3 Langerhans cell histiocytosis (LCH), one pituicytoma, one granular cell tumor and one chronic inflammation. Patients were given subsequent treatment, however given the time this report has been written, it is too early to obtain any post-surgery MRI from these nine patients (Table 2).

\section{Discussion}

Up till now, very few reports have shared experiences in dealing with PST patients. We therefore conducted this retrospective case review in order to characterize its various facets of imaging characteristics and clinical manifestations, and gain a better understanding of the differential effects of available treatments.

In our cohort, the average age of PST patients was 27.6 years and $43.4 \%$ of the patients were aged under

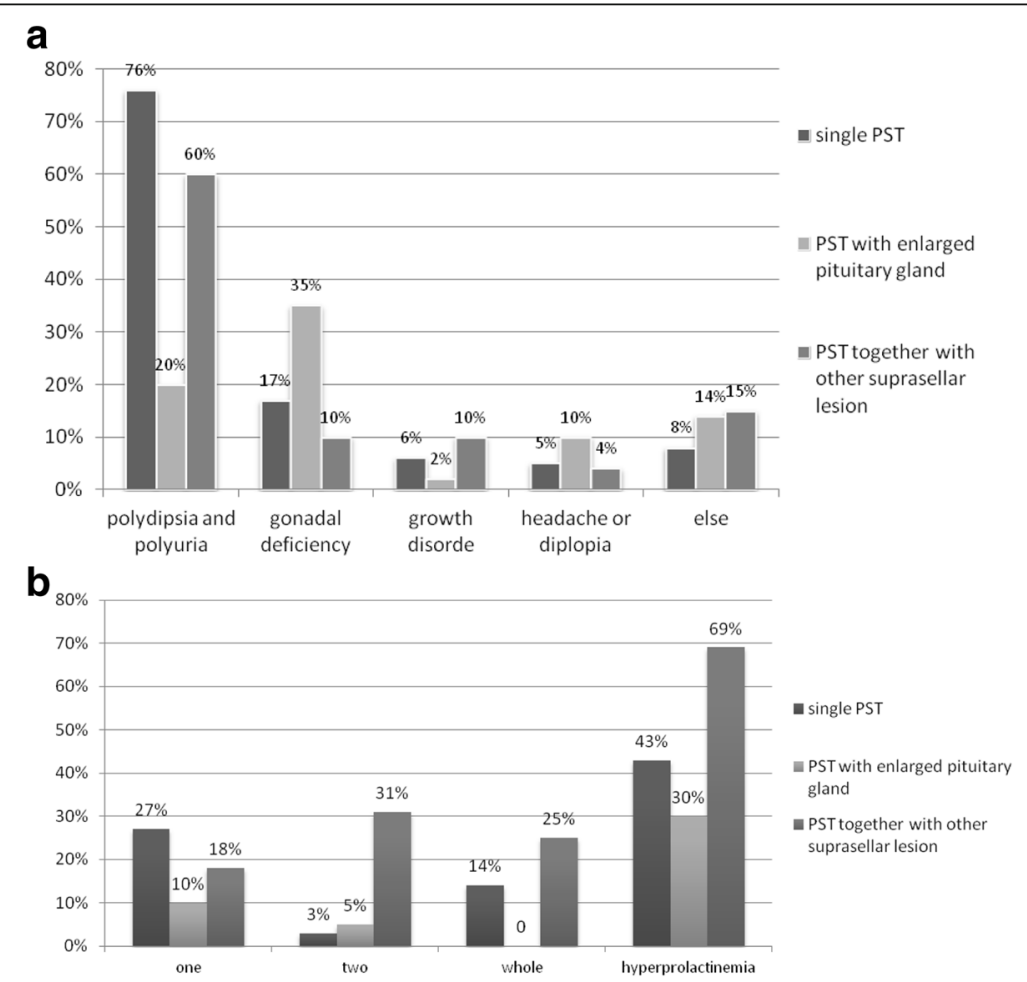

Fig. 4 Relationship between SR-MRI and clinical presentations or pituitary function. a: MRI findings and clinical presentations. b: MRI findings and pituitary function 


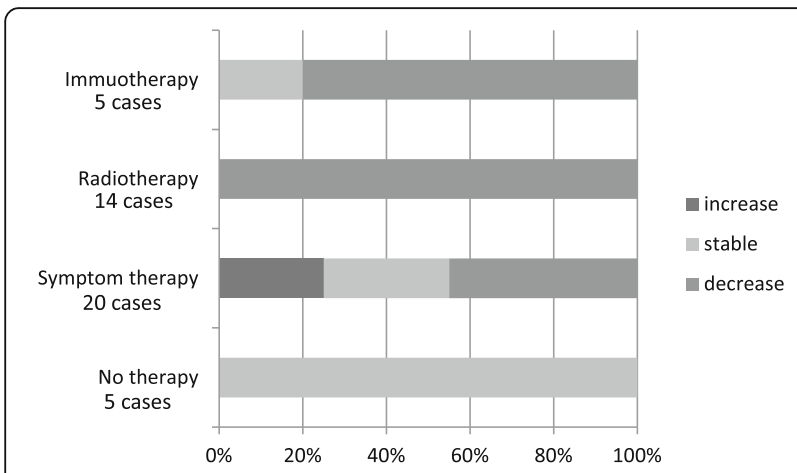

Fig. 5 Different therapy and MRI changes. Five patients didn't receive any treatment but underwent regular follow-up didn't indicate any noticeable change. Of the 20 patients who received symptomatic treatment, the thickness of pituitary stalks were decreased in nearly half of them (nine cases), unaltered in six patients and increased in five patients. All 14 patients receiving radiotherapy showed shrinkage in the thickness of pituitary stalk. Among five cases receiving immunosuppressed therapy, four cases showed shrinkage while one case showed no change

$21 \mathrm{yr}$, which strongly suggested the fact that PST is mostly seen in the young adults and teenagers.

This result is to some extent in agreement with the evidences shown in a number of previous reports [9-11], which stated that patients with PST were mostly between 7 and 13 years old.

However, another recent review [12] reported an average age around 44 years old in patients with PST. Such difference may result from distinct patient groups, as this report reviewed specifically the adult population.

Indeed, another study [13] reported 37 cases of PST together with central diabetes insipidus (CDI) and showed that the average age at initial diagnosis is 29 years old, which is similar to our cohort.
Additionally, females accounted for over $84 \%$ in the age group between 30 and 35 years, which was indicative of the fact that women in their childbearing age are susceptible to PST.

Clinical manifestations such as polyuria and polydipsia are the major reasons that patients see a physician at the first place. In Fig. 2 the five most common clinical manifestations were shown in our PST patients, which include polyuria and polydipsia, gonadal disorder (amenorrhea in female or loss of libido in male in our context), growth disorder, headache as well as diplopia (a sign of lesion enlargement).

It is worth noting that these manifestations distribute differently in the various age groups. Polyuria together with polydipsia and growth disorder are more commonly seen in teenagers whereas headache or diplopia are often complained by the middle-aged patients.

An explanation for such different manifestations may lie in the distinct underlying etiology. Headache or diplopia is more common in the adult patients, mostly due to the sellar mass as its enlargement could suppress optic nerve [1]. In comparison, teenagers resort to the physician mostly because of polyuria and polyuria which are caused by germinoma or LCH [14].

To a clinical physician, it presents a great challenge to make decision about effective treatment to individual patient without confirmed etiology. However, the age and clinical manifestations can help to make decisions.

In 2007, Hamilton [1] reported 65 cases of pituitary stalk lesions and they concluded that $\mathrm{LCH}$ and germinoma were the two dominant diseases that caused PST in children, whereas the inflammatory was the numberone disease that gave rise to PST in adult. Since the publication of this report, our decision-making process of treating PST patients was biased in favor of the Hamilton's conclusions. More specifically, we strategically

Table 2 Cases who had surgeries or biopsies

\begin{tabular}{|c|c|c|c|c|}
\hline Case & Sex & Age at diagnose & Clinical presentation & Diagnose \\
\hline 1 & $\mathrm{~F}$ & 10 & $\begin{array}{l}\text { Polyuria and } \\
\text { growth disorder }\end{array}$ & Germinoma \\
\hline 2 & M & 35 & polyuria & Germinoma \\
\hline 3 & $\mathrm{~F}$ & 21 & polyuria & $\begin{array}{l}\text { Langerhans cell } \\
\text { histiocytosis }\end{array}$ \\
\hline 4 & $\mathrm{~F}$ & 5 & polyuria & Germinoma \\
\hline 5 & $\mathrm{~F}$ & 40 & polyuria & Granular cell tumor \\
\hline 6 & M & 45 & polyuria & $\begin{array}{l}\text { Langerhans cell } \\
\text { histiocytosis }\end{array}$ \\
\hline 7 & M & 18 & polyuria & $\begin{array}{l}\text { Langerhans cell } \\
\text { histiocytosis }\end{array}$ \\
\hline 8 & $\mathrm{~F}$ & 10 & $\begin{array}{l}\text { polyuria and } \\
\text { amenorrhea }\end{array}$ & Chronic inflammatory \\
\hline 9 & $\mathrm{~F}$ & 15 & $\begin{array}{l}\text { polyuria and } \\
\text { amenorrhea }\end{array}$ & Pituicytoma \\
\hline
\end{tabular}


divided patient groups by age, drawing a line at 35 years. On one hand, it is widely acknowledged that both germinoma and LCH are sensitive to radiotherapy, for that reason we administered radiotherapy to all 12 patients under $21 \mathrm{y}$ as well as two adults under 35. It turned out to be effective. On the other hand, we held the view that most middle-aged patients are more likely to have inflammatory lesions and thus immuno-suppressed therapy was administered to five patients above 35 years. It worked in 4 patients. Besides, in our nine definitivelydiagnosed patients, five confirmed with either germinoma or $\mathrm{LCH}$ were under 35.

\section{Additional remarks}

PST is a rare disease and most of the clinical physicians are not yet familiar with that. Towards making the final decision of treatment and predicting future progression of the disease, evaluation of anterior pituitary function and sellar region MRI are two absolutely necessary procedures. In addition, the clinical manifestation and age of the patients could play more important roles than what we ever thought of before.

Nathan J. reported a remarkable discovery lately, concluding that DI and anterior pituitary dysfunction may sever as twin causal indicators to estimate in an all-or-none fashion the likelihood of having neoplastic process in PST patients [11]. Our results showed that two-third of polydipsia and polyuria patients were confirmed as diabetes insipidus and about half of the patients were reported to have at least 1 anterior pituitary dysfunction who took the evaluation. Although a causal interrelationship cannot be derived from available weak statistical inference, there is emerging evidence that clinical presentation together with imaging and functional evaluation could form a diagnostic triangle to pin down the casual link between symptoms and underlying pathologies. And our experience indeed surprised us that given supplementary information from the clinical presentation, an early PST onset combined with DI and hypopituitarism helps make precise prediction about neoplasm. As for neoplastic lesions, we recommend radiotherapy and immuno-suppressed therapy is our first choice for female patients during their childbearing age.

We propose that a full picture of correlation between PST and anterior pituitary function and the connection to how they interact with clinical manifestation to convey essential information to the physician in the decision-making process, calls for a systematic clinicresearch data collection workflow. Once such workflow becomes available, separately-scattered dots from three diverged diagnostic approaches can converge to valuable inferences and lead to more effective treatment strategies.

\section{Conclusion}

PST is most commonly seen in the teenagers in the adolescence and the women in the childbearing ages. Distinct etiology may be identified purely based on the dominant clinical manifestations in combination with age, which in our case contributed markedly to the final decision of treatments. Given our results, radiotherapy and immuotherapy seem to work as the twin silverbullets, selectively alleviating clinical symptoms and shrink the visible stalk thickening of two different groups of patients.

\section{Abbreviations \\ ACTH: Adrenocorticotropic hormone; CDI: Central diabetes insipidus; DI: Diabetes insipidus; E2: Estraliol; F: Fludrocortisol; FSH: Follicle-stimulating hormone; FT3:: Free triiodothyronine; FT4: Free thyroxine; GH: Growth hormone; IGF-1: Insulin-like growth factor type 1; ITT: Insulin tolerance test; LCH: Langerhans cell histiocytosis; LH: Luteotropic hormone; P: Progesterone; PRL: Prolactin; PST: Pituitary stalk thickening; SR-MRI: Sellar region MRI; \\ T: Testosterone; TSH: Thyroid Stimulating Hormone; UFC: Urinary free cortisol}

\section{Acknowledgements}

The whole study was completed with the cooperation between the neurosurgery and endocrinology team of Huashan Hospital. Besides, our colleges of radiology department and laboratory helped a lot.

Funding

The study was supported by Science and Technology Commission of Shanghai Municipality (CN) 11411951900.

\section{Availability of data and materials}

The dataset supporting the conclusions of this article is not available because all the clinical data involves patients' privacy and no informed consent was made.

\section{Authors' contributions}

YJ C and XF S collected the data and drafted the manuscript. ZY Z revised the language and grammar of the manuscript. HY Y, Y Z, YF W and R X provided the clinical data and searched literatures. SQ $L$ and $Y M L$ conceived and designed the experiments. All authors read and approved the final manuscript.

\section{Competing interests}

The authors declare that they have no competing interests.

\section{Ethics approval and consent to participate}

All procedures performed in studies involving human participants were in accordance with the ethical standards of the institutional research committee.

\section{Author details \\ 'Department of Endocrinology and Metabolism, Huashan Hospital, Shanghai Medical College, Fudan University, 12 Wulumugi Zhong Road, Shanghai 200040, China. ${ }^{2}$ Department of Neurosurgery, Huashan Hospital, Shanghai Medical College, Fudan University, 12 Wulumuqi Zhong Road, Shanghai 200040, China.}

Received: 4 June 2016 Accepted: 8 December 2016 Published online: 06 April 2017

\footnotetext{
Reference

1. Hamilton BE, Salzman KL, Osborn AG. Anatomic and pathologic spectrum of pituitary infundibulum lesions. Am J Roentgenol. 2007;188:223-32.

2. Satogami N, Miki Y, Koyama T, Kataoka M, Togashi K. Normal pituitary stalk: high-resolution MR imaging at 3 T. AJNR Am J Neuroradiol. 2010;31:355-9.

3. Rupp D, Molitch M. Pituitary stalk lesions. Curr Opin Endocrinol Diabetes Obes. 2008;15:339-45.
} 
4. Janmohamed S, Grossman AB, Metcalfe K, Lowe DG, Wood DF, Chew SL, Monson JP, Besser GM, Plowman PN. Suprasellar germ cell tumours: specific problems and the evolution of optimal management with a combined chemoradiotherapy regimen. J Clin Endocrinol (Oxf). 2002:57:487-500.

5. Leger J, Velasquez A, Garel C, Hassan M, Czernichow P. Thickened pituitary stalk on magnetic resonance imaging in children with central diabetes insipidus. J Clin Endocrinol Metab. 1999;84(6):1954-60.

6. Oelkers W. Adrenal insufficiency. New Engl J Med. 1996;335(16):1206-12.

7. Liang L, Korogi Y, Sugahara T, Ikushima I, Shigematsu Y, Okuda T, Takahashi M, Kochi M, Ushio Y. MRl of intracranial germ cell tumours. Neuroradiology. 2002:44:382-8.

8. Lipscombe L, Asa SL, Ezzat S. Management of lesions of the pituitary stalk and hypothalamus. Endocrinologist. 2003;13(1):38-51.

9. Kaltsas GA, Powles TB, Evanson J, Plowman PN, Drinkwater JE, Jenkins PJ, Monson JP, Besser GM, Grossman AB. Hypothalamo-pituitary abnormalities in adult patients with Langerhans cell histiocytosis: clinical, endocrinological, and radiological features and response to treatment. J Clin Endocrinol Metab. 2000;85(4):1370-6.

10. Maghnie M, Cosi G, Genovese E, Manca-Bitti ML, Cohen A, Zecca S, Tinelli C, Gallucci M, Bernasconi S, Boscherini B, et al. Central diabetes insipidus in children and young adults. N Engl J Med. 2000;343(14):998-1007.

11. Robison NJ, Prabhu SP, Sun P, Chi SN, Kieran MW, Manley PE, Cohen LE, Goumnerova L, Smith ER, Scott RM, London WB, Ullrich NJ. Predictors of neoplastic disease in children with isolated pituitary stalk thickening. Pediatr Blood Cancer. 2013;60:1630-5.

12. Turcu AF, Erickson BJ, Lin E, Guadalix S, Schwartz K, Scheithauer BW, Atkinson JL, Young Jr WF. Pituitary stalk lesions:the mayo clinic experience. J Clin Endocrinol Metab. 2013;98(5):1812-8.

13. Jian F, Bian L, Sun S, Yang J, Chen X, Chen Y, Ma Q, Miao F, Wang W, Ning G, Sun Q. Surgical biopsies in patients with central diabetes insipidus and thickened pituitary stalks. Endocrine. 2014;47(1):325-35.

14. Tien RD, Newton TH, McDermott MW, Dillon WP, Kucharczyk J. Thickened pituitary stalk on MR images in patients with diabetes insipidus and Langerhans cell histiocytosis. AJNR Am J Neuroradiol. 1990;11(4):703-8.

\section{Submit your next manuscript to BioMed Central and we will help you at every step:}

- We accept pre-submission inquiries

- Our selector tool helps you to find the most relevant journal

- We provide round the clock customer support

- Convenient online submission

- Thorough peer review

- Inclusion in PubMed and all major indexing services

- Maximum visibility for your research

Submit your manuscript at www.biomedcentral.com/submit

) Biomed Central 